\title{
Research
}

\section{Psychological morbidity and return to work after injury:}

\author{
multicentre cohort study
}

\begin{abstract}
\section{Background}

The benefits of work for physical, psychological, and financial wellbeing are well documented. Return to work (RTW) after unintentional injury is often delayed, and psychological morbidity may contribute to this delay. The impact of psychological morbidity on RTW after a wide range of unintentional injuries in the UK has not been adequately quantified.
\end{abstract}

\section{Aim}

To quantify the role of psychological factors, including anxiety, depression, and post-traumatic distress, on RTW following unintentional injuries.

\section{Design and setting}

A longitudinal multicentre prospective study was undertaken in Nottingham, Bristol, Leicester, and Guildford, UK.

\section{Method}

Participants ( $n=273$ ) were 16-69-year-olds admitted to hospital following unintentional injury, who were in paid employment prior to injury. They were surveyed at baseline, then at 1, 2, 4, and 12 months following injury; demographic data were collected along with injury characteristics, psychological morbidity, and RTW status Associations between demographic, injury and psychological factors, and RTW between 2 and 12 months after injury were quantified using random effects logistic regression.

\section{Results}

The odds of RTW between 2 and 12 months after injury reduced as depression scores early in the recovery period (1 month after injury) increased lodds ratio [OR] $0.87,95 \%$ confidence interval $[\mathrm{Cl}=0.79$ to 0.95 ) and as length of hospital stay increased (OR $0.91,95 \% \mathrm{Cl}$ ) 0.86 to 0.96 ). For those experiencing threatening life events following injury (OR $0.27,95 \% \mathrm{Cl}=0.10$ to 0.72 ) and with higher scores on the Crisis Support Scale $[\mathrm{OR} 0.93,95 \% \mathrm{Cl}]=0.88$ to 0.99 ), the odds of RTW between 2 and 12 months after injury were lower. Multiple imputation analysis found similar results, but those relating to crisis support did not remain statistically significant.

\section{Conclusion}

Primary care professionals can identify patients at risk of delayed RTW who may benefit from management of psychological morbidity and support to RTW.

\section{Keywords}

cohort study; injuries; mental health

psychological factors; work

\section{INTRODUCTION}

Being in work benefits physical and mental health, ${ }^{1}$ while being out of work can have negative financial, physical, and psychological consequences. ${ }^{2}$ The importance of identifying modifiable factors that, if addressed, may help individuals to remain in work was highlighted by the 2008 report, Working for a Healthier Tomorrow. ${ }^{2}$

In England in 2014-2015, 319000 adults aged 16-69 years were admitted to hospital with traumatic injuries or poisoning (external cause codes V01-X59). ${ }^{3}$ The annual NHS costs of care in the first 12 months after such injuries has recently been estimated at $€ 1.53$ billion. ${ }^{4}$ Hospital-treated injuries result in substantial health-related work absence, with $17 \%$ of emergency department attenders and $43 \%$ of people admitted to hospital not having returned to work 4 months post-injury. ${ }^{5}$ Injuries also account for $10 \%$ of sick notes in the $\mathrm{UK}^{2}$ and $14 \%$ of benefit claimants. ${ }^{6}$

Depression, ${ }^{7-11}$ anxiety, ${ }^{12}$ and posttraumatic stress disorder (PTSD) ${ }^{13}$ are common after traumatic injury; for example, a review focusing on road traffic injuries estimated that, at 1 year, prevalence ranged from $21-67 \%$ for depression,

D Kendrick, MSc, DM, FRCGP, MFPH, professor of primary care research; $\mathbf{C}$ Coupland, $\mathrm{PhD}$, professor of medical statistics in primary care: J Whitehead, MBBS, academic clinical fellow in general practice; School of Medicine; S Joseph, MSc, PhD, DipCouns, professor of psychology, health and social care, School of Education; R Morriss, PhD, professor of psychiatry and community mental health, Division of Psychiatry and Applied Psychology, University of Nottingham, Nottingham. P Dhiman, PhD, research fellow, Research Design Service East Midlands, Queen's Medical Centre, Nottingham. B Kellezi, $\mathrm{PhD}$, lecturer/senior lecturer, Department of Psychology, Nottingham Trent University, Nottingham. K Beckett, BSc, SRN, RM, NIHR knowledge mobilisation research fellow, University of the West of England, Bristol. N Christie, PhD, senior lecturer, Centre for Transport Studies,
4-87\% for anxiety, and 0-100\% for PTSD. ${ }^{14}$ These conditions have a negative impact on an individual's ability to return to work (RTW); $8,13,15-20$ this has been illustrated in a study by Ching et al, who found that fewer patients with depression (52\%) or PTSD (47\%) were working 6 months after injury than those without depression $(73 \%)$ or PTSD (78\%). ${ }^{20}$

As depression, anxiety, and PTSD are detectable and treatable, it is important to quantify their impact on RTW among injured working-age adults in the UK. This article reports the findings on psychological morbidity and RTW from the Impact of Injuries Study, to inform the identification and management of these diagnoses postinjury in primary care and in other services, such as occupational health.

\section{METHOD}

Elements of the study method are outlined below; a full description is available in the published protocol..$^{21}$

\section{Study design}

This research involved a multicentre longitudinal cohort study undertaken in four NHS acute hospital trusts with
University College London, London. J Sleney, MSc research fellow and postgraduate researcher. Department of Sociology, University of Surrey. J Barnes, PhD, lecturer, Loughborough Design School, Loughborough University, Loughborough. Address for correspondence

Denise Kendrick, School of Medicine, Division of Primary Care, University of Nottingham, Tower Building, University Park, Nottingham, NG7 2RD, UK. E-mail: denise.kendrickanottingham.ac.uk Submitted: 23 November 2016; Editor's response: 19 December 2016; final acceptance: 22 January 2017.

CBritish Journal of General Practice

This is the full-length article (published online 20 Jun 2017) of an abridged version published in print. Cite this version as: Br J Gen Pract 2017; DOI: https://doi.org/10.3399/bjgp17X691673 


\section{How this fits in}

Injuries are common in working-age adults, resulting in a delayed return to work (RTW) for many. This is of concern as the benefits of work for physical, psychological, and financial wellbeing are well documented. Depression that occurs early in the recovery period, threatening life events after the injury, and a longer stay in hospital significantly reduce the odds of RTW between 2 and 12 months after injury. Primary care professionals can identify patients at risk of delayed RTW, detect and manage psychological morbidity, and provide RTW support.

emergency departments in Nottingham, Bristol, Leicester, and Guildford, UK. These sites were chosen due to their having prior experience of recruiting to similar studies.

\section{Participants}

Participants were recruited from June 2010 until June 2012 within 3 weeks of hospital admission for unintentional injury. Those aged $16-70$ years with a fixed address (to enable follow-up) were eligible. Those with loss of consciousness, amnesia, or a Glasgow Coma Scale score of $<15$ at presentation were excluded due to difficulty distinguishing between head injury sequelae and psychological morbidity. ${ }^{22}$
Participants were recruited face to face and by post. Quota sampling by injury type was used from June 2010 until May 2011; subsequently, due to slow recruitment, all eligible patients could participate.

The sample for this analysis comprised participants who were in paid employment at baseline, and returned the 1-month questionnaire and at least one subsequent follow-up questionnaire lat 2,4 , or 12 months).

\section{Data collection}

Participants completed self-administered questionnaires at recruitment (baseline) and at 1,2, 4, and 12 months post-injury. Baseline questionnaires assessed:

- sociodemographic characteristics lage, marital status, ethnicity, employment status, and area-level deprivation based on the 2010 indices of multiple deprivation); ${ }^{23}$

- injury details;

- long-term health conditions (longstanding illness, past psychiatric diagnoses, and pain);

- anxiety and depression; ${ }^{24}$

- alcohol problems; ${ }^{25}$

- substance use; ${ }^{26}$ and

- social functioning. ${ }^{27}$

Injury severity was assessed from medical records based on the most severe

\section{Table 1. Description and reliability scores of scales used}

\begin{tabular}{|c|c|c|c|c|}
\hline \multirow[b]{2}{*}{ Variable } & \multirow[b]{2}{*}{ Scale } & \multicolumn{2}{|c|}{ Description } & \multirow[b]{2}{*}{ Cronbach's $\alpha$} \\
\hline & & Items, $n$ & Score & \\
\hline Anxiety and depression & $\begin{array}{l}\text { Hospital Anxiety } \\
\text { and Depression Scale }\end{array}$ & $\begin{array}{l}\text { 14: } 7 \text { depression, } \\
7 \text { anxiety }\end{array}$ & $\begin{array}{l}\text { 0-21 for each subscale (higher } \\
\text { scores indicate higher severity } \\
\text { of anxiety and depression) }\end{array}$ & $\begin{array}{c}0.80 \text { (anxiety) } \\
0.70 \text { (depression) } \\
0.83 \text { (overall) }\end{array}$ \\
\hline Alcohol problems & $\begin{array}{l}\text { Alcohol Use Disorders } \\
\text { Identification Test }\end{array}$ & 10 & $\begin{array}{l}\text { 0-40 (higher scores indicate } \\
\text { higher levels of excessive } \\
\text { or harmful drinking) }\end{array}$ & 0.79 \\
\hline Substance use & Drug Abuse Screening Test & 10 & $\begin{array}{l}\text { 0-10 (higher scores indicate } \\
\text { higher levels of abuse of } \\
\text { substances other than alcohol) }\end{array}$ & 0.67 \\
\hline Social functioning & $\begin{array}{l}\text { Social Functioning } \\
\text { Questionnaire }\end{array}$ & 8 & $\begin{array}{l}\text { 0-24 (higher scores indicate } \\
\text { greater social dysfunction) }\end{array}$ & 0.72 \\
\hline $\begin{array}{l}\text { Post-traumatic } \\
\text { distress }\end{array}$ & Impact of Events Scale & $\begin{array}{l}\text { 15: } 7 \text { on intrusion, } \\
8 \text { on avoidance } \\
\text { symptoms }\end{array}$ & $\begin{array}{l}\text { 0-75 (higher scores indicate } \\
\text { greater severity of } \\
\text { post-traumatic symptoms) }\end{array}$ & $\begin{array}{c}0.89 \text { (intrusion) } \\
0.84 \text { (avoidance) } \\
0.92 \text { (overall) }\end{array}$ \\
\hline Social support & Crisis Support Scale & 6 & $\begin{array}{l}\text { 6-42 (higher scores indicate } \\
\text { higher social support) }\end{array}$ & 0.76 \\
\hline $\begin{array}{l}\text { Positive and negative } \\
\text { changes in outlook }\end{array}$ & $\begin{array}{l}\text { Changes in Outlook } \\
\text { Questionnaire }\end{array}$ & $\begin{array}{l}\text { 10: } 5 \text { on positive change, } \\
5 \text { on negative change }\end{array}$ & $\begin{array}{l}\text { 5-30 for each subscale (higher } \\
\text { scores indicate respective greater } \\
\text { positive and negative changes) }\end{array}$ & $\begin{array}{l}0.78 \text { (negative) } \\
0.87 \text { (positive) }\end{array}$ \\
\hline
\end{tabular}




\section{Box 1. Predictors and potential predictors of return to work included in multivariable model building}

\section{Block 1 la-priori predictors)}

Age, sex, study centre, and time

Block 2 (psychological predictors at 1 month)

HADS-A, HADS-D, IES-A, IES-I, AUDIT and DAST

\section{Block 3 (potential predictors at baseline)}

Number of past psychiatric diagnoses, HADS-A, HADS-D, AUDIT, DAST, longstanding illness, work status, ethnicity, deprivation, marital status, length of hospital stay, injury characteristics / severity, number, body part, mechanism, and location]

\section{Block 4 (potential predictors at 1 month)}

Social functioning, social support, changes in outlook (positive and negative), threatening life events since injury, pain visual analogue scale, compensation, and litigation

AUDIT = Alcohol Use Disorders Identification Test. DAST = Drug Abuse Screening Test. HADS-A = Hospital Anxiety and Depression Scale - anxiety. HADS-D = Hospital Anxiety and Depression Scale - depression. IES-A = Impact of Events Scale avoidance. Impact of Events Scale-I =IES intrusion.
- minor (AIS score: 1);

- moderate (AIS score: 2); and

- serious or worse (AIS score: $\geq 3-6$ ).

Follow-up questionnaires included questions on:

- time off work since injury;

- self-reported recovery; $^{29}$

- post-traumatic distress; ${ }^{30}$

- threatening life events related to the injury; ${ }^{31}$

- social support; 32

- positive and negative changes in outlook; ${ }^{33}$ and

- legal proceedings or compensation claims due to injury.

More information about the scale that was used to measure each variable is given in Table 1. injury for participants with multiple injuries and using the Abbreviated Injury Scale (AIS). ${ }^{28}$ The following categories were used:

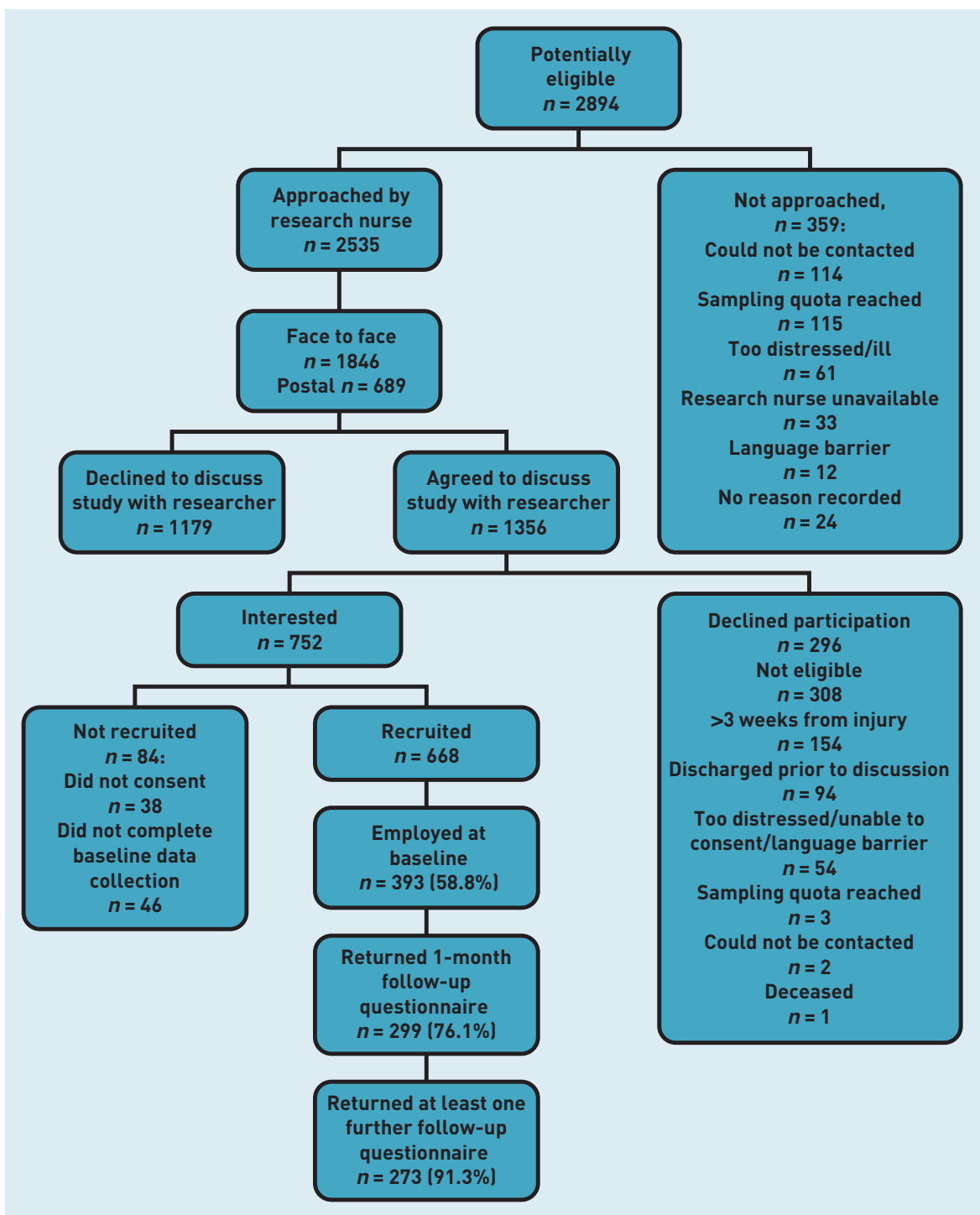


Table 2. Participants' baseline characteristics $(n=273)$

\begin{tabular}{|c|c|}
\hline Characteristic & Participants ${ }^{\mathrm{a}}$ \\
\hline \multicolumn{2}{|l|}{ Study site, $n(\%)$} \\
\hline Nottingham & $99(36.3)$ \\
\hline Leicester & $74(27.1)$ \\
\hline Bristol & $71(26.0)$ \\
\hline Guildford & $29(10.6)$ \\
\hline \multicolumn{2}{|l|}{ Age, years, $n[\%]$} \\
\hline $16-24$ & $29(10.6)$ \\
\hline $25-44$ & $92(33.7)$ \\
\hline $45-64$ & $145(53.1)$ \\
\hline $65-69$ & $7(2.6)$ \\
\hline \multicolumn{2}{|l|}{ Sex, $n(\%)$} \\
\hline Female & $132(48.4)$ \\
\hline Male & $141(51.7)$ \\
\hline \multicolumn{2}{|l|}{ Ethnic group, $n[\%]$} \\
\hline White & $265(97.1)$ \\
\hline Black or ethnic minority & $8(2.9)$ \\
\hline \multicolumn{2}{|l|}{ Deprivation } \\
\hline IMD score, median (IQR) [3] ${ }^{\mathrm{b}}$ & $12(7-20)$ \\
\hline \multicolumn{2}{|l|}{ Marital status, $n(\%)$} \\
\hline Single & $74(27.1)$ \\
\hline Married/partnership & $164(60.1)$ \\
\hline Divorced/widowed & 35 (12.8) \\
\hline \multicolumn{2}{|l|}{ Longstanding illness, $n(\%)[1]^{\mathrm{b}}$} \\
\hline No & 230 (84.3) \\
\hline Yes & $42(15.4)$ \\
\hline \multicolumn{2}{|l|}{ Past psychiatric diagnoses (obtained from SCID), $n(\%)$} \\
\hline 0 & 237 (86.8) \\
\hline 1 & $27(9.9)$ \\
\hline$\geq 2$ & $9(3.3)$ \\
\hline HADS-A score, median (IQR) [1] ${ }^{\mathrm{b}}$ & $2(0-4)$ \\
\hline HADS-D score, median (IQR) [1] ${ }^{\mathrm{b}}$ & $0(0-2)$ \\
\hline AUDIT score, median (IQR) [5] & $4(2-6)$ \\
\hline DAST score, median (IQR) [2] & $0(0-0)$ \\
\hline Social functioning score, median (IQR) & $1(0-3)$ \\
\hline Pain visual analogue scale score, median (IQR) [1] & $0(0-2)$ \\
\hline Nights in hospital, median (IQR) [11] ${ }^{\mathrm{b}}$ & $5.5(3-8)$ \\
\hline \multicolumn{2}{|l|}{ Injury severity, $n(\%)[1]^{\mathrm{b}}$} \\
\hline Minor (AIS = 1) & $15(5.5)$ \\
\hline Moderate (AIS = 2) & $206(75.7)$ \\
\hline Serious or worse (AIS $\geq 3$ ) & 51 (18.8) \\
\hline \multicolumn{2}{|l|}{ Injuries, $n(\%)$} \\
\hline 1 & $117(42.9)$ \\
\hline 2 & $91(33.3)$ \\
\hline$\geq 3$ & $65(23.8)$ \\
\hline \multicolumn{2}{|l|}{ Body part injured, $n$ [\%] } \\
\hline Other & $28(10.3)$ \\
\hline Upper limb & 49 (18.0) \\
\hline Lower limb & $170(62.3)$ \\
\hline Upper and lower limbs & $26(9.5)$ \\
\hline \multicolumn{2}{|l|}{ Injury mechanism, $n(\%)$} \\
\hline Other & 28 (10.3) \\
\hline Falls & $159(58.2)$ \\
\hline Traffic & $63(23.1)$ \\
\hline Struck & $23(8.4)$ \\
\hline
\end{tabular}

Researchers administered structured clinical interviews ${ }^{34}$ to measure psychological morbidity for all participants at baseline.

\section{Outcomes}

The primary outcome was whether a participant reported returning to work. This was a binary outcome at each time point (1, 2, 4, and 12 months post-injury). RTW was defined as being in full- or part-time paid employment, working at the specific time point, and not being prevented from working since the previous follow-up because of the injury sustained.

\section{Statistical analyses}

Baseline characteristics were described and compared between the sample described above (responders) and those employed at baseline who returned the 1-month questionnaire only (non-responders). Categorical data were compared using $\chi^{2}$ tests, and continuous data using $t$-tests or Mann-Whitney $U$ tests, dependent on distributions.

Proportions of participants who had returned to work were calculated, and an RTW trajectory was developed. ${ }^{35}$ Nonresponders and those with missing RTW data were categorised as 'unknown'.

Univariate and multivariable odds ratios (ORs) with $95 \%$ confidence intervals (Cls) were estimated for RTW using random effects logistic regression to account for repeated measures of RTW at 2, 4, and 12 months. Linearity of continuous predictors was assessed, and non-linear predictors were categorised into quintiles. Models were built using predictors described in Box 1.

Block 2 psychological predictors at 1 month were added to Block 1 in order of statistical significance on univariate analysis, and retained if the likelihood ratio test (LRT) $P$-value was $<0.05$. Correlations between predictors in Blocks 3 and 4 with psychological predictors of Block 2 were assessed. Those with correlation coefficients of $\geq 0.5$ or $\leq-0.5$ were excluded from the analysis.

Block 3 predictors were added and retained in the model if the LRT was $P<0.05$ or if their removal resulted in $a>10 \%$ change in the 1-month psychological predictor OR. Block 4 predictors were added and retained as for Block 3. Interactions between psychological predictors at 1 month and age, sex, and follow-up time were assessed based on an LRT $P$-value of $<0.01$.

Collinearity was assessed by the covariance correlation matrix and variance 
Table 2 continued. Participants' baseline characteristics ( $n=273$ )

$\begin{array}{ll}\text { Place of injury, } n[\%][1]^{\mathbf{b}} & \\ \text { Other } & 42(15.4) \\ \text { Home } & 39(14.3) \\ \text { Work } & 83(30.4) \\ \text { Road } & 29(10.6) \\ \text { Countryside } & 38(13.9) \\ \text { Sports facilities } & 41(15.0)\end{array}$

${ }^{a}$ Participants employed at baseline who returned 1-month questionnaire and at least one follow-up questionnaire. ${ }^{b}$ [missing]. AIS = Abbreviated Injury Scale. AUDIT = Alcohol Use Disorders Identification Test. DAST = Drug Abuse Screening Test. HADS-A = Hospital Anxiety and Depression Scale - anxiety. HADS-D = Hospital Anxiety and Depression Scale - depression. $I M D=$ Index of Multiple Deprivation. $I Q R=$ interquartile range. $S C I D=$ structured clinical interview. with RTW are shown in Tables 3 and 4 respectively. In the final model, a oneunit increase in the Hospital Anxiety and Depression Scale - depression (HADS-D) score reduced the odds of RTW by $13.0 \%$ (OR 0.87, $95 \% \mathrm{Cl}=0.79$ to 0.95 ), a one-unit increase in the number of nights in hospital reduced the odds of RTW by $9.2 \%$ (OR 0.91, $95 \% \mathrm{Cl}=0.86$ to 0.96 ), the odds of RTW reduced by $6.7 \%$ per unit increase in crisis support (OR $0.93,95 \% \mathrm{Cl}=0.88$ to 0.99 ), and by $72.7 \%$ for those experiencing threatening life events since the injury IOR $0.27,95 \%$ $\mathrm{Cl}=0.10$ to 0.72 ). Social functioning and negative changes in outlook were excluded due to high correlations with the HADS-D at 1 month. No statistically significant interactions between depression at 1 month and age, sex, and time were found. Variance inflation factors ranged from 1.03 to 3.08 (data not shown).

Non-responders were statistically significantly younger $(P<0.001)$, more likely to be male $(P<0.001)$, single $(P<0.001)$, live in disadvantaged areas $(P<0.001)$, and have scores indicating greater problems with alcohol $(P=0.001)$ and drug use $(P=0.01)$ than responders (data not shown). Results from the multiple imputation analysis (Table 4) were similar to the complete case analysis. Associations between depression at 1 month (OR $0.91,95 \% \mathrm{Cl}=0.85$ to 0.99 ), nights in hospital (OR $0.92,95 \% \mathrm{Cl}=0.88$ to 0.97), and threatening life events (OR $0.42,95 \% \mathrm{Cl}=0.19$ to 0.92 ) remained statistically significant. Crisis support no longer remained statistically significantly associated with RTW IOR 0.97. 95\% Cl = 0.92 to 1.03$)$.

\section{DISCUSSION}

\section{Summary}

One-third of participants had not returned to work at 12 months post-injury. An increased depression score at 1 month post-injury, increased hospital stay, subsequent threatening life events, and increased Crisis Support Scale score were associated with significantly lower odds of RTW after injury. Other sociodemographic and injury characteristics, such as age, sex, body part injured, or injury severity, were not independently associated with RTW status. Findings for depression, length of hospital stay, and threatening life events remained statistically significant in multiple imputation analyses.

\section{Strengths and limitations}

One strength of this study is that it is the first prospective, multicentre, UK study to quantify the impact of early 


\section{Table 3. Potential factors associated with return to work}

\begin{tabular}{lc} 
Variable & Unadjusted OR (95\% Cl) \\
\hline Location & \\
Centre & 1.00 \\
Nottingham & $0.82(0.51$ to 1.31$)$ \\
Leicester & $0.92(0.57$ to 1.48$)$ \\
Bristol & $1.96(1.00$ to 3.84$)$ \\
Guildford & \\
\hline Age, years & 1.00 \\
$16-24$ & $1.29(0.67$ to 2.51$)$ \\
$25-44$ & $0.95(0.51$ to 1.76$)$ \\
$45-64$ & $0.65(0.19$ to 2.28$)$ \\
65-69 & \\
\hline Sex & 1.00 \\
Female & $1.04(0.71$ to 1.51$)$ \\
Male & \\
\hline Follow-up time, months & 1.00 \\
2 & $11.72(6.06$ to 22.70$)$ \\
4 & $77.39(30.91$ to 193.77$)$ \\
12 & \\
\hline Psychological predictors at 1 month post-injury & $0.92(0.88$ to 0.97$)$ \\
HADS-A & $0.92(0.88$ to 0.96$)$ \\
HADS-D & $0.96(0.93$ to 0.98$)$ \\
IES-A & $0.96(0.94$ to 0.99$)$ \\
IES-1 & \\
AUDIT scale, quintile & 1.00 \\
1 (0) & $1.08(0.64$ to 1.83$)$ \\
$2(1.0-2.0)$ & $1.73(0.95$ to 3.16$)$ \\
$3(2.2-3.0)$ & $2.12(1.19$ to 3.76$)$ \\
$4(3.3-6.0)$ & $1.16(0.65$ to 2.05$)$ \\
5 (7.0-25.0) & $1.08(0.69$ to 1.67$)$ \\
DAST scale &
\end{tabular}

\section{Psychological predictors at baseline}

Past psychiatric diagnoses (obtained from SCID)

0

$\geq 2$

HADS-A

HADS-D

AUDIT scale

DAST scale

1.00

0.8810 .46 to 1.68$)$

$0.27(0.09$ to 0.80$)$

0.99 (0.93 to 1.05$)$

$0.94(0.85$ to 1.04$)$

$1.00(0.96$ to 1.04$)$

$0.92(0.61$ to 1.37$)$

\section{Longstanding illness}

No

1.00

Yes

0.76 (0.46 to 1.27$)$

\section{Ethnic group}

White

1.00

Black or minority ethnic group

$0.43(0.12$ to 1.48$)$

Deprivation (IMD)

Marital status

Single

0.98 (0.97 to 1.00 )

Married/partnership

Divorced/widowed

$1.43(0.92$ to 2.22$)$

1.17 (0.62 to 2.20 )

Nights in hospital

0.93 (0.90 to 0.97)

\section{Injury severity}

Minor (AIS = 1)

Moderate (AIS = 2)

0.73 (0.32 to 1.63 )

Serious or worse (AIS $\geq 3$ )

$0.42(0.17$ to 1.02$)$

\section{Number of injuries}

2

$\geq 3$ psychological morbidity on RTW in adults aged 16-69 years, who were admitted to hospital following a range of injuries. It also addressed some limitations of previous studies by including a general injury population with injuries of varying levels of severity, measuring a series of psychological predictors of RTW, and adjusting for several potential confounders. Despite responders differing from nonresponders on a range of characteristics, multiple imputation analyses showed that most of the findings were robust to missing data. Follow-up rates were higher than, or comparable with, those of studies that used similar recruitment methods. ${ }^{38-42}$

Limitations include a potential selection bias: $30 \%$ of eligible patients who were approached took part, and participants and non-participants may have differed in terms of their likelihood of returning to work. It was also not possible to explore the impact of injuries on changes to jobs and hours of work; further work is required to address this.

The number of participants with some types of injuries (for example, penetrating injuries or over-exertion injures such as sprains) was small, limiting analyses to broad injury groupings. The upper limb, lower limb, upper and lower limbs, and other injuries categories were chosen because limb injuries are a major cause of work disability ${ }^{43-45}$ and the groups were consistent with a systematic review of prognostic factors associated with RTW post-injury. ${ }^{46}$ Similarly, small numbers required broad grouping of injury mechanisms.

Study sites were in the Midlands and southern England. Occupations vary across the country and 'blue-collar work' (for example, manual labour or work paid by the hour) has previously been associated with lower rates of RTW post-injury; ${ }^{46}$ as such, some care should be taken in generalising the findings to the north of the country.

Black and minority ethnic groups were under-represented, potentially limiting the generalisability of these findings.

Injuries that take place at work are likely to have poorerwork-related outcomes than those occurring elsewhere; $42,47,48$ this may be partly explained by depression and PTSD, which may be more common after occupational injuries. ${ }^{849-51}$ With only 83 participants who suffered work-related injuries, the predictors and RTW were not explored in this group as this study was underpowered to detect significant associations between predictors and RTW in this group.

The finding of lower odds of RTW with increasing crisis support was unexpected, 


\section{Table 3 continued. Potential factors associated with return to work}

\begin{tabular}{lc} 
Body part injured & 1.00 \\
Other & $0.95(0.46$ to 1.96$)$ \\
Upper limb & $0.55(0.29$ to 1.04$)$ \\
Lower limb & $0.45(0.19$ to 1.03$)$ \\
Upper and lower limbs & 1.00 \\
\hline Injury mechanism & $1.00(0.54$ to 1.84$)$ \\
Other & $0.75(0.38$ to 1.49$)$ \\
Falls & $1.10(0.47$ to 2.57$)$ \\
Traffic & \\
Struck & 1.00 \\
\hline Place of injury & $0.63(0.32$ to 1.22$)$ \\
Other & $0.70(0.40$ to 1.24$)$ \\
Home & $0.90(0.44$ to 1.85$)$ \\
Work & $1.28(0.64$ to 2.55$)$ \\
Road & $0.61(0.31$ to 1.17$)$
\end{tabular}

\section{Other predictors at 1 month post-injury}

Social functioning scale, quintile $1(0-4.6)^{a}$

$2(5-6.9)$

$3(7-8)$

$4(9-10)$

$5(10.3-18.3)$

CCS

CiOQ-P scale

CiOQ-N scale

1.00

$0.42(0.24$ to 0.73$)$

$0.31(0.18$ to 0.54$)$

$0.29(0.16$ to 0.52$)$

$0.23(0.13$ to 0.42$)$

1.00 (0.97 to 1.04$)$

$0.96(0.94$ to 0.98$)$

0.97 (0.93 to 1.01 )

\section{Threatening life events since injury}

No

Yes

1.00

$0.38(0.22$ to 0.66$)$

Pain visual analogue scale

\section{Seeking compensation}

No

Yes

Involved in litigation

No

Yes
${ }^{a}$ Figures in brackets represent the range for each quintile. AIS = Abbreviated Injury Scale. AUDIT=Alcohol Use Disorders Identification Test. CIOQ-N = Changes in Outlook Questionnaire (negative). CIOQ-P= Changes in Outlook Questionnaire (positive). CSS = Crisis Support Scale. DAST = Drug Abuse Screening Test. HADS-A= Hospital Anxiety and Depression Scale - anxiety. HADS-D = Hospital Anxiety and Depression Scale - depression. IES-A = Impact of Events Scale avoidance. IES-I I Impact of Events Scale intrusion. IMD = Index of Multiple Deprivation. $I Q R=$ interquartile range. $O R=$ odds ratio. $S C I D=$ structured clinical interview with delayed RTW, 19,52,53 but differences in occupations, benefits, and compensation systems limit comparability with the UK. A 2010 systematic review of RTW prognostic factors after acute orthopaedic trauma ${ }^{46}$ included only two small UK studies; the authors of the research presented here have not found any more recent UK studies.

One cohort study from 2002 recruited 154 injured males admitted to hospital and found greater PTSD symptoms were associated with a reduced odds of RTW 18 months post-injury (regression coefficient Impact of Event Scale- $\mathrm{R}$ avoidance subscale 0.47, 95\% Cl not reported, $P<0.0011$. 42 Another study, from 1992 - a review of the records of 101 patients receiving compensation having sustained injury in road traffic accidents - found that undefined psychological problems (regression coefficient 3.24, standard error [SE] 1.54) and older age (regression coefficient -0.77 , SE 0.39) were associated with a reduced likelihood of RTW. $^{54}$ In the study presented here, no association between PTSD symptoms and RTW was found, once depression was in the multivariable model. This may be explained by the fact that depression and PTSD often coexist. ${ }^{55}$ Most ( $81 \%$ ) of the current study's participants with moderate or severe PTSD met borderline or case criteria for depression and/or anxiety. Injuries due to assaults $^{42}$ and road traffic accidents ${ }^{54}$ were more frequent than in the study presented here, and PTSD may be more common after such injuries.

Differences in study populations may explain the variation between the findings presented here and those of other studies in relation to sex $^{42}$ and age. ${ }^{54}$ the larger sample size of this study may explain the statistically significant finding for length of hospital stay.

\section{Implications for research and practice}

Patients consult frequently in primary care after injury, ${ }^{5}$ hence a range of primary care professionals, including GPs, are well placed to identify psychological morbidity post-injury. Most injured patients have not returned to work 1 month after injury and would be eligible for the Fit for Work service, according to guidance from the UK government. ${ }^{56}$ This service provides occupational health assessments and develops an RTW plan with patients: the findings presented here suggest assessments should include identifying, and responding to, psychological morbidity.

This study identified a small number of key factors - depression, longer in-patient stays, threatening life events subsequent 


\section{Table 4. Psychological and other predictors associated with return to work at 1 month post-injury}

\begin{tabular}{|c|c|c|}
\hline & $\begin{array}{l}\text { Final model (complete } \\
\text { case analysis) }\end{array}$ & $\begin{array}{l}\text { Final model (multiple } \\
\text { imputation analysis) }\end{array}$ \\
\hline Characteristic & OR $(95 \% \mathrm{Cl})$ & OR $(95 \% \mathrm{Cl})$ \\
\hline \multicolumn{3}{|l|}{ Location } \\
\hline \multicolumn{3}{|l|}{ Centre } \\
\hline Nottingham & 1.00 & 1.00 \\
\hline Leicester & $0.86(0.40$ to 1.85$)$ & $0.90(0.48$ to 1.71$)$ \\
\hline Bristol & $0.68(0.31$ to 1.48$)$ & 0.95 (0.52 to 1.73$)$ \\
\hline Guildford & $2.62(0.92$ to 7.50$)$ & 1.97 (0.81 to 4.80$)$ \\
\hline \multicolumn{3}{|l|}{ Age, years } \\
\hline $16-24$ & 1.00 & 1.00 \\
\hline $25-44$ & 1.13 (0.39 to 3.29$)$ & 0.95 (0.44 to 2.08) \\
\hline 45-64 & 0.44 (0.16 to 1.24 ) & $0.60(0.27$ to 1.31$)$ \\
\hline $65-69$ & $0.27(0.04$ to 1.99$)$ & 0.31 (0.06 to 1.68$)$ \\
\hline \multicolumn{3}{|l|}{ Sex } \\
\hline Female & 1.00 & 1.00 \\
\hline Male & 0.73 (0.39 to 1.34 ) & 0.79 (0.45 to 1.38$)$ \\
\hline \multicolumn{3}{|c|}{ Follow-up time, months } \\
\hline 2 & 1.00 & 1.00 \\
\hline 4 & $10.80(5.62$ to 20.76$)$ & 7.16 (3.61 to 14.19 ) \\
\hline 12 & 72.17 (29.02 to 179.45$)$ & $31.78(13.87$ to 72.81$)$ \\
\hline \multicolumn{3}{|c|}{ Psychological predictors at 1 month post-injury } \\
\hline HADS-D & 0.87 (0.79 to 0.95 ) & 0.91 (0.85 to 0.99) \\
\hline \multicolumn{3}{|c|}{ Psychological, sociodemographic, and injury characteristics at baseline } \\
\hline Nights in hospital & $0.91(0.86$ to 0.96$)$ & $0.92(0.88$ to 0.97$)$ \\
\hline \multicolumn{3}{|c|}{ Other predictors at 1 month post-injury } \\
\hline CSS & 0.93 (0.88 to 0.99) & 0.97 (0.92 to 1.03 ) \\
\hline \multicolumn{3}{|c|}{ Threatening life events since injury } \\
\hline No & 1.00 & 1.00 \\
\hline Yes & 0.27 (0.10 to 0.72 ) & 0.42 (0.19 to 0.92 ) \\
\hline
\end{tabular}

\section{Funding}

This study was funded by the National Institute for Health Research (NIHR) Collaboration for Leadership in Applied Health Research and Care (CLAHRC) Nottinghamshire, Derbyshire, and Lincolnshire. Richard Morriss is currently funded by NIHR CLAHRC East Midlands. The views expressed are those of the authors and not necessarily of the NHS, NIHR, or the Department of Health.

\section{Ethical approval}

Ethical approval for the study was provided by Nottingham Research Ethics Committee 1 (ref. 09/H0407/29).

\section{Provenance}

Freely submitted; externally peer reviewed.

\section{Competing interests}

The authors have declared no competing interests.

\section{Discuss this article}

Contribute and read comments about this article: bjgp.org/letters to injury, and greater crisis support that predicted longer work absence. GPs, occupational health services, and the Fit for Work service can use these findings to identify those patients who may benefit from additional help with returning to work.

Some GPs may regard depressive symptoms almost as 'normal' after an injury and are reluctant to medicalise unhappiness. ${ }^{57}$ Watchful waiting may be appropriate for short-lived symptoms, but this study shows the negative impact of depressive symptoms that last for 1 month or more post-injury. The National Institute for Health and Care Excellence (NICE) guideline on recognising and managing depression in adults with chronic physical health problems highlights the high risk of depression where functional impairment is present..$^{58}$ Thus, as traumatic injuries requiring hospital admission frequently result in functional impairments for many months, ${ }^{41,59}$ these NICE guidelines should be applied.

Traumatic injuries present additional challenges for GPs in terms of managing depression, such as impaired mobility, which can limit access to group-based peer support, talking therapies, or undertaking physical activity; analgesics and adjuvant pain medications may also interact with antidepressants.

Further work exploring GPs' perceptions of psychological problems post-injury, the extent and ways in which they identify, manage, and coordinate care for these patients, and barriers and facilitators to doing so would be useful. Longitudinal studies assessing the impact of psychological problems on RTW after acute traumatic occupational injuries would also be beneficial, as this group may be at particular risk of experiencing psychological problems. 


\section{REFERENCES}

1. Waddell G, Burton AK. Is work good for your health and well-being? An evidence review. Norwich: TSO, 2006. https://www.gov.uk/government/publications/ is-work-good-for-your-health-and-well-being laccessed 16 May 2017).

2. Black C. Working for a healthier tomorrow. Dame Carol Black's review of the health of Britain's working age population. London: TSO, 2008. https://uww.gov. uk/government/uploads/system/uploads/attachment_data/file/209782/hwwbworking-for-a-healthier-tomorrow.pdf (accessed 16 May 2017).

3. NHS Digital. Hospital Episode Statistics, Admitted Patient Care - England, 2014-15. http://content.digital.nhs.uk/searchcatalogue?productid=19420\&q=title $\% 3 a \% 22$ Hospital+Episode+Statistics\%2c+Admitted+patient+care+-+England\%2 2\&sort=Relevance\&size=10\&page=1\#top (accessed 16 May 2017).

4. Kellezi B, Baines DL, Coupland C, et al. The impact of injuries on health service resource use and costs in primary and secondary care in the English NHS. J Public Health (Oxf) 2015; ii: fdv173.

5. Kendrick D, Vinogradova Y, Coupland C, et al. Getting back to work after injury: the UK Burden of Injury multicentre longitudinal study. BMC Public Health 2012; 12: 584.

6. Black C. Frost D. Health at work: an independent review of sickness absence. London: TSO, 2011. https://www.gov.uk/government/uploads/system/uploads/ attachment_data/file/181060/health-at-work.pdf (accessed 19 May 2017).

7. Bültmann U, Franche R-L, Hogg-Johnson S, et al. Health status, work limitations, and return-to-work trajectories in injured workers with musculoskeletal disorders. Qual Life Res 2007; 16(7): 1167-1178.

8. Carnide N, Franche R-L, Hogg-Johnson S, et al. Course of depressive symptoms following a workplace injury: a 12-month follow-up update. J Occup Rehabil 2016; 26(2): 204-215

9. Lin KH, Shiao JS, Guo NW, et al. Long-term psychological outcome of workers after occupational injury: prevalence and risk factors. J Occup Rehabil 2014 24(1): 1-10.

10. Vles WJ, Steyerberg EW, Essink-Bot ML, et al. Prevalence and determinants of disabilities and return to work after major trauma. J Trauma 2005; 58(1): 126-135.

11. Wall CL, Ogloff JRP, Morrissey SA. Psychological consequences of work injury: personality, trauma and psychological distress symptoms of noninjured workers and injured workers returning to, or remaining at work. Int J Disability Management 2007; 2(2): 37-46.

12. Noble J, Gomez M, Fish JS. Quality of life and return to work following electrical burns. Burns 2006; 32(2): 159-164

13. Zatzick D, Jurkovich G, Rivara FP, et al. A national US study of posttraumatic stress disorder, depression, and work and functional outcomes after hospitalization for traumatic injury. Ann Surg 2008; 248(3): 429-437.

14. Blaszczynski A, Gordon K, Silove D, et al. Psychiatric morbidity following motor vehicle accidents: a review of methodological issues. Compr Psychiatry 1998; 39(3): 111-121.

15. Ash P, Goldstein SI. Predictors of returning to work. Bull Am Acad Psychiatry Law 1995; 23(2): 205-210.

16. Franche RL, Carnide N, Hogg-Johnson S, et al. Course, diagnosis, and treatment of depressive symptomatology in workers following a workplace injury: a prospective cohort study. Can J Psychiatry 2009; 54(8): 534-546.

17. Matthews LR. Work potential of road accident survivors with post-traumatic stress disorder. Behav Res Ther 2005; 43(4): 475-483.

18. Opsteegh L, Reinders-Messelink HA, Schollier D, et al. Determinants of return to work in patients with hand disorders and hand injuries. J Occup Rehabil 2009; 19(3): 245-255

19. Tøien K, Skogstad L, Ekeberg $\emptyset$, et al. Prevalence and predictors of return to work in hospitalised trauma patients during the first year after discharge: a prospective cohort study. Injury 2012; 43(9): 1606-1613

20. Ching AC, Wessler $L$, Blizzard SR, et al. The relation between depression, PTSD and the likelihood of returning to work after spine trauma. Spine J 2014; 14(11):

21. Kendrick D, O'Brien C, Christie N, et al. The impact of injuries study. Multicentre study assessing physical, psychological, social and occupational functioning post injury - a protocol. BMC Public Health 2011; 11(1): 963.

22. Jacobson RR. The post-concussional syndrome: physiogenesis, psychogenesis and malingering. An integrative model. J Psychosom Res 1995; 39(6): 675-693.

23. Department for Communities and Local Government. English Indices of Deprivation 2010. London: Department for Communities and Local
Government, 2011. https://www.gov.uk/government/statistics/english-indicesof-deprivation-2010 (accessed 15 May 2017).

24. Bjelland I, Dahl AA, Haug TT, Neckelmann D. The validity of the Hospital Anxiety and Depression Scale: an updated literature review. J Psychosom Res 2002; 52(2): 69-77.

25. Saunders JB, Aasland OG, Babor TF, et al. Development of the Alcohol Use Disorders Identification Test (AUDIT): WHO Collaborative Project on Early Detection of Persons with Harmful Alcohol Consumption-II. Addiction 1993; 88: 791-804

26. Maisto SA, Carey MP, Carey KB, et al. Use of the AUDIT and the DAST-10 to identify alcohol and drug use disorders among adults with a severe and persistent mental illness. Psychol Assess 2000; 12(2): 186-192.

27. Tyrer $P$, Nur U, Crawford $M$, et al. The Social Functioning Questionnaire: a rapid and robust measure of perceived functioning. Int J Soc Psychiatry 2005; 51(3): 265-275.

28. Association for the Advancement of Automotive Medicine. Abbreviated Injury Scale (AIS) 2005 - update 2008. 2008. https://www.aaam.org/abbreviated-injuryscale-ais/ laccessed 24 May 2017)

29. Harms L. After the accident: survivors' perceptions of recovery following road trauma. Aust Soc Work 2004; 57(2): 161-174.

30. Horowitz M, Wilner N, Alvarez W. Impact of Event Scale: a measure of subjective stress. Psychosom Med 1979; 41(3): 209-218.

31. Brugha T, Bebbington $P$, Tennant $C$, Hurry J. The list of threatening experiences: a subset of 12 life event categories with considerable long-term contextual threat. Psychol Med 1985; 15(1): 189-194.

32. Joseph S, Andrews B, Williams R, Yule W. Crisis support and psychiatric symptomatology in adult survivors of the Jupiter cruise ship disaster. $\mathrm{Br} J \mathrm{Clin}$ Psychol 1992; 31(Pt 1): 63-73.

33. Joseph S, Linley PA, Andrews L, et al. Assessing positive and negative changes in the aftermath of adversity: psychometric evaluation of the changes in outlook questionnaire. Psychol Assess 2005; 17(1): 70-80.

34. First MB, Gibbon M, Spitzer RL, Williams JBW. User's guide for the structured clinical interview for DSM-IV-TR axis I disorders - research version. New York, NY: Biometrics Research, New York State Psychiatric Institute, 2002.

35. Harcombe H, Langley J, Davie G, Derrett S. Functional status following injury: what recovery pathways do people follow? Injury 2015; 46(7): 1275-1280.

36. Rubin DB. Multiple imputation for nonresponse in surveys. New York, NY: John Wiley \& Sons, 2004

37. Royston P. Multiple imputation of missing values. Stata Journal $2004 ; \mathbf{4 ( 3 )}$ 227-241.

38. Polinder S, van Beeck EF, Essink-Bot ML, et al. Functional outcome at 2,5, 5, 9 , and 24 months after injury in the Netherlands. J Trauma 2007; 62(1): 133-141.

39. Wilson R, Hansen P. Langley J, Derrett S. A comparison of injured patient and general population valuations of EQ-5D health states for New Zealand. Health Qual Life Outcomes 2014; 12: 21.

40. Kendrick D, Vinogradova Y, Coupland C, et al. Recovery from injury: the UK burden of injury multicentre longitudinal study. Inj Prev 2013; 19(6): 370-381.

41. Meerding WJ, Looman CWN, Essink-Bot M-L, et al. Distribution and determinants of health and work status in a comprehensive population of injury patients. J Trauma 2004; 56(1): 150-161.

42. Mason S, Wardrope J, Turpin G, Rowlands A. Outcomes after injury: comparison of workplace and nonworkplace injury. J Trauma 2002; 53(1): 98-103.

43. MacKenzie EJ, Bosse MJ, Kellam JF, et al. Early predictors of long-term work disability after major limb trauma. J Trauma 2006; 61(3): 688-694.

44. Pichora D, Grant H. Upper extremity injured workers stratified by current work status: an examination of health characteristics, work limitations and work instability. Int J Occup Environ Med 2010; 1(3): 124-131.

45. Read KM, Kufera JA, Dischinger PC, et al. Life-altering outcomes after lower extremity injury sustained in motor vehicle crashes. J Trauma 2004; 57(4): 815-823.

46. Clay FJ, Newstead SV, McClure RJ. A systematic review of early prognostic factors for return to work following acute orthopaedic trauma. Injury 2010; 41(8): 787-803.

47. Schneider JC, Bassi S, Ryan CM. Employment outcomes after burn injury: a comparison of those burned at work and those burned outside of work. J Burn Care Res 2011; 32(2): 294-301.

48. Lilley R, Davie G, Langley J, et al. Do outcomes differ between work and nonwork-related injury in a universal injury compensation system? Findings from 
the New Zealand Prospective Outcomes of Injury Study. BMC Public Health 2013; 13: 995.

49. Kim J. Depression as a psychosocial consequence of occupational injury in the US working population: findings from the medical expenditure panel survey. BMC Public Health 2013;13: 303

50. Ghisi M, Novara C, Buodo G, et al. Psychological distress and post-traumatic symptoms following occupational accidents. Behav Sci2013; 3(4): 587-600.

51. Buodo G, Novara C, Ghisi M, Palomba D. Posttraumatic and depressive symptoms in victims of occupational accidents. Depress Res Treat 2012: 2012: 184572

52. Zatzick D, Jurkovich GJ, Rivara FP, et al. A national US study of posttraumatic stress disorder, depression, and work and functional outcomes after hospitalization for traumatic injury. Ann Surg 2008; 248(3): 429-437.

53. Richmond TS, Amsterdam JD, Guo W, et al. The effect of post-injury depression on return to pre-injury function: a prospective cohort study. Psychol Med 2009; 39(10): 1709-1720.
54. Cornes P. Return to work of road accident victims claiming compensation for personal injury. Injury 1992; 23(4): 256-260.

55. O'Donnell ML, Creamer M, Pattison P. Posttraumatic stress disorder and depression following trauma: understanding comorbidity. Am J Psychiatry 2004; 161(8): 1390-1396

56. Department for Work and Pensions. Fit for work: guidance for GPS. 2015 https://www.gov.uk/government/uploads/system/uploads/attachment_data/ file/458954/gp-fit-for-work-gps.pdf (accessed 19 May 2017)

57. Christie N, Beckett K, Earthy S, et al. Seeking support after hospitalisation for injury: a nested qualitative study of the role of primary care. Br J Gen Pract 2016; DOI: https://doi.org/10.3399/bjgp15X688141.

58. National Institute for Health and Care Excellence. Depression in adults with a chronic physical health problem: recognition and management. CG91. London: NICE, 2009. https://www.nice.org.uk/guidance/cg91 laccessed 5 Jun 2017).

59. Holbrook TL, Anderson JP, Sieber WJ, et al. Outcome after major trauma: 12-month and 18-month follow-up results from the Trauma Recovery Project. $J$ Trauma 1999; 46(5): 765-771; discussion 771-773. 